\title{
Methylenetetrahydrofolate reductase (MTHFR) C677T polymorphism in psoriasis in southern Turkey*
}

\author{
Muzeyyen Izmirli ${ }^{1}$ \\ Eminenur Rifaioglu ${ }^{1}$ \\ Ozgur Aldemir ${ }^{1}$ \\ Ozlem Ekiz ${ }^{1}$
}

\author{
Bilge Bulbul Sen ${ }^{1}$ \\ Bulent Gogebakan ${ }^{1}$ \\ Tuba Sen ${ }^{1}$ \\ Davut Alptekin ${ }^{2}$
}

DOI: http:/ /dx.doi.org/10.1590/abd1806-4841.20164766

\begin{abstract}
BACKGROUND: Psoriasis is a multigenic and multifactorial dermatological disease linked to cardiovascular diseases. Increased levels of homocysteine in patients with psoriasis have been demonstrated in many studies. The most frequently investigated genetic defect that plays a role in homocysteine metabolism is single point substitution (C to T) located on the 677 th nucleotide of the methylenetetrahydrofolate reductase gene (MTHFR).

Овјестіvе:In this study, we aimed to investigate methylenetetrahydrofolate C677T polymorphism in psoriasis patients in Turkey.

METHODs:The study included 96 patients with psoriasis and 77 controls from southern Turkey. Methylenetetrahydrofolate C677T polymorphism was analysed using the Polymerase Chain Reaction-Restriction Fragment Length Polymorphism methods.

RESULTs:In the psoriasis group, 34 CC (35.4\%), 46 CT (47.9\%) and 16 TT (16.7\%) genotypes were found, respectively; while in the control group, the figures were 39 (50.6\%), 35 (45.5\%), $3(3.9 \%)$. Homozygote and heterozygote T alleles of methylenetetrahydrofolate C677T polymorphism were significantly higher in the psoriasis than in the control group ( $\mathrm{p}=0.013$ ). CONCLUSION:We firstly found a correlation between methylenetetrahydrofolate C677T polymorphism and psoriasis among the southern Turkish population.
\end{abstract}

Keywords: Methylenetetrahydrofolate Reductase (NADPH2); Polymorphism, single nucleotide; Psoriasis; Turkey

\section{INTRODUCTION}

Psoriasis, which affects $1-3 \%$ of the world's population, is a multifactorial, dermatological disease. ${ }^{1}$ It is associated with genetic and environmental factors. ${ }^{2,3}$ Previous studies reported that psoriasis patients were found to have a two-fold increased risk of cardiovascular disease compared with healthy individuals. ${ }^{4,5}$ Furthermore, some studies reported increased levels of plasma homocysteine and a decreased folic acid concentration in psoriasis patients. ${ }^{4,6}$ Today, hyperhomocysteinemia is a recognised risk factor for cardiovascular diseases and psoriasis.,

The MTHFR enzyme plays a major role in homocysteine and folic acid metabolism. This enzyme is responsible for the irreversible conversion to 5 methyl tetrahydrofolate, which is a methyl donor of 5,10 methylenetetrahydrofolate. ${ }^{8}$ The MTHFR is located on the 1 p36.3 locus and many polymorphisms have been identified in the MTHFR. ${ }^{9} \mathrm{C}$ to $\mathrm{T}$ substitution in the MTHFR is located on the $677^{\text {th }}$ nucleotide, a missense mutation on the 4 th exon. MTHFR C677T polymorphism results in a valine to alanine exchange at the $222^{\text {nd }}$ codon. This leads to an MTHFR enzyme with decreased enzymatic activity. Mutation is the most common genetic cause of increased homocysteine levels. ${ }^{10}$ These frequently seen polymorphisms were found to be associated with cardiovascular diseases, cancer, chronic idiopathic acrocyanosis and homocysteinemia, which is a risk factor for developing psoriasis. ${ }^{8,11-13}$

Our research was geared towards investigating MTHFR C677T polymorphism in psoriasis patients in southern Turkey.

Received on 28.05.2015

Approved by the Advisory Board and accepted for publication on 12.09.2015

* Work performed at the Mustafa Kemal University, Medical School - Hatay, Turkey.

Financial Support: Mustafa Kemal University Research Fund (BAP:11780).

Conflict of Interest: None.

Mustafa Kemal University, Medical School - Hatay, Turkey.

Cukurova University, Medical School - Adana, Turkey.

C 2016 by Anais Brasileiros de Dermatologia 


\section{METHODS}

\section{Study Population}

This study and all experimental procedures were approved by the Local Ethics Committee of Mustafa Kemal University, Hatay, Turkey. Written informed consent was obtained from each participant. Patients were diagnosed with psoriasis in the dermatology department of Mustafa Kemal University, at Medical Faculty Hospitals. The psoriasis areas and severity indexes of 96 psoriatic patients were assessed. ${ }^{14}$ The control group was selected randomly and comprised 77 psoriasis-free individuals whose relatives were also psoriasis-free.

\section{Sample preparation}

Four $\mathrm{ml}$ of venous blood were taken from the subjects and transferred to tubes with EDTA. The DNA isolation of the blood samples collected from both groups was performed by a salting out method and the DNA samples were stored $+4 \mathrm{C}^{\circ} .{ }^{15}$

\section{Genotype assessment}

MTHFR C677T polymorphism was analysed using PCRRFLP methods. The PCR amplification applied the following forward primers: 5' TGA AGG AGA AGG TGT CTG CGG GA 3'; and the reverse primers $5^{\prime}$ AGG ACG GTG CGG TGA GAG TG 3' and the 198 base pair (bp) were amplified. The PCR conditions used have been described by Izmirli et al.. ${ }^{11}$ The PCR product was digested with Hinf I for 3 hours at $37.0^{\circ} \mathrm{C}$. Finally, the genotype was assessed on a $10 \%$ polyacrylamide gel via by UV transilluminator.

\section{Statistical Analysis}

The data were analysed statistically with the SPSS version 20 program $\left(\mathrm{IBM}^{\circledast}\right)$. To compare the categorical parameters, the Chi-square test was used. The distribution status of the values was determined through the Kolmogorov-Smirnov test. To compare the numerical values, two tests were applied: if the distribution of the values was normal, the Student's T test was used; while the MannWhitney $U$ test was employed if values were not normal.

\section{RESULTS}

The mean ages of the psoriasis and control group were $43.7 \pm 1.8$ and $49.2 \pm 0.8$, respectively $(p<0.05)$. There were 49 males and 47 females in the psoriasis group; and 67 males and 10 females in the control group $(\mathrm{p}<0.05)$ (Table 1$)$. The minimum, maximum and mean duration periods of the disease were $0.5,43$ and 10.3 years, respectively. The patients' minimum, maximum and mean PASI values were $0.60,25$, and 7.84 , respectively. CC, CT and TT genotypes of MTHFR C677T polymorphism were found, respectively, in $34(35.4 \%), 46(47.9 \%), 16(16.7 \%)$ subjects from the psoriasis group; and in $39(50.6 \%), 35(45.5 \%), 3(3.9 \%)$ subjects from the control group ( $\mathrm{p}=0.013$ ) (Table 2). CC and CT+TT genotypes of $\mathrm{MTH}$ FR C677T polymorphism were found, respectively, in 34 (35.4\%), $62(64.6 \%)$ subjects from the psoriasis group; and in 39 (50.6\%), 38 (49.4) subjects from the control group $(\mathrm{p}=0.031)$ (Table 3$)$.

Moreover, no relationship was found between the positive family history and early onset of psoriasis or MTHFR C677T polymorphism $(p=0.451, \mathrm{p}=0.127)$.
TABLE 1: Demographic features of patients and controls

\begin{tabular}{llll}
\hline & $\begin{array}{l}\text { Psoriasis } \\
(\mathbf{n}=\mathbf{9 6})\end{array}$ & $\begin{array}{l}\text { Control } \\
(\mathbf{n}=77)\end{array}$ & p value \\
\hline Age & 43.27 & 49.23 & $<0.05$ \\
Gender & $49^{*} / 47^{* *}$ & $67^{*} / 10^{* *}$ & $<0.05$ \\
Body Mass Index & 28.09 & 29.13 & 0.529 \\
PASI & 7.8 & & \\
\hline
\end{tabular}

* Male; ** Female

TABLE 2: CC, CT and TT genotypes of MTHFR C677T gene polymorphism in patient and control groups

\begin{tabular}{lllll}
\hline MTHFR C677T & CC & CT & TT & $p$ value \\
\hline $\begin{array}{l}\text { Psoriasis group } \\
(\mathrm{n}=96)(\%)\end{array}$ & $34(35.4)$ & $46(47.9)$ & $16(16.7)$ & $\mathrm{p}=0.013$ \\
$\begin{array}{l}\text { Control group } \\
(\mathrm{n}=77)(\%)\end{array}$ & $39(50.6)$ & $35(45.5)$ & $3(3.9)$ & \\
\hline
\end{tabular}

TABLE 3: CC and CT and TT genotypes of MTHFR C677T polymorphism in patient and control groups

\begin{tabular}{llll}
\hline MTHFR C677T & CC & CT+TT & $p$ value \\
\hline Psoriasis group $(n=96)(\%)$ & $34(35.4)$ & $62(64.6)$ & $p=0.031$ \\
Control group $(n=77)(\%)$ & $39(50.6)$ & $38(49.4)$ & $p=0.031$ \\
\hline
\end{tabular}

\section{DISCUSSION}

In this study, we found that MTHFR C677T polymorphism influences the risk of psoriasis in southern Turkey. We show that there are significant differences between psoriasis and controls for mentioned polymorphism. In addition, our study was the first report on psoriasis patients from southern Turkey, the population of which is ethnically distinct from that of other Turkish regions.

In previous studies, significant links of varying degrees were found between MTHFR C677T polymorphism and psoriasis. ${ }^{13,16}$ The initial study on this relationship was performed in Chinese patients by Baiqui et al. in 2000. They found an increased TT genotype of MTHFR C677T polymorphism in psoriasis patients, compared with the control group. ${ }^{16}$ Vasku et al. investigated MTHFR C677T polymorphisms in patients from the Czech Republic and found an increased frequency of the CC genotype compared with the control group. ${ }^{13}$ However, in their study, the TT genotype was more frequent only in psoriasis patients with a positive family history of the disease. Moreover, certain data from studies show that there is increase of the psoriasis risk for MTHFR C677T polymorphism in northern Turkey and Iran. ${ }^{17,18}$ Our results support the aforementioned studies, as we found that the TT genotype was higher in the psoriasis group than in the control group $(p=0.013)$. Nevertheless, some studies, including of Malaysian and Caucasian individuals, found no association between psoriasis and controls for MTHFR C677T polymorphism. ${ }^{19,20}$ These contradictory results may be attributable to ethnic differences.

MTHFR C677T polymorphism is important for drug usage. 
Methotrexate inhibits the dihydrofolate reductase enzyme, which plays a key role in the folate cycle. ${ }^{6}$ Only four studies have stated that polymorphisms of the MTHFR gene could be associated with methotrexate efficacy in psoriasis patients. ${ }^{21-24}$ Chandran et al. and Campalani et al. demonstrated that MTHFR 677TT polymorphism may be related to methotrexate-induced liver toxicity in Canadian and UK populations, respectively. ${ }^{21-22}$ However, Taraborelli et al. and Warren et al. could not identify any significant differences of MTHFR C677T polymorphism in Italian and UK populations, respective$1 y .{ }^{23-24}$

\section{REFERENCES}

1. Rachakonda TD, Schupp CW, Armstrong AW. Psoriasis prevalence among adults in the United States. J Am Acad Dermatol. 2014;70:512-6.

2. Balato N, Di Costanzo L, Patruno C, Patri A, Ayala F. Effect of weather and environmental factors on the clinical course of psoriasis. Occup Environ Med. 2013;70:600.

3. Roberson ED, Bowcock AM. Psoriasis genetics: breaking the barrier. Trends Genet. 2010;26:415-23

4. Tobin AM, Hughes R, Hand EB, Leong T, Graham IM, Kirby B. Homocysteine status and cardiovascular risk factors in patients with psoriasis: a case-control study. Clin Exp Dermatol. 2011;36:19-23.

5. Malerba M, Gisondi P, Radaeli A, Sala R, Calzavara Pinton PG, Girolomoni G. et al. Plasma homocysteine and folate levels in patients with chronic plaque psoriasis. Br J Dermatol. 2006;155:1165-9.

6. Silva MF, Fortes MR, Miot LD, Marques SA. Psoriasis: correlation between severity index (PASI) and quality of life index (DLQI) in patients assessed before and after systemic treatment. An Bras Dermatol. 2013;88:760-3

7. Richetta AG, Mattozzi C, Macaluso L, Cantisani C, Giancristoforo S, D'epiro S, et al. Homocysteine plasmatic status in patients with psoriasis. Eur $\mathrm{J}$ Dermatol. 2011;21:621-3

8. Sampogna F, Camaioni DB, Giampetruzzi AR, Corona R, Ruzzi L, Silvestri L, et al. Chronic idiopathic acrocyanosis and methylenetetrahydrofolate reductase C677T (p.Ala222Val) and A1298C (p.Glu429Ala) polymorphisms. Eur J Dermatol. 2013;23:356-61.

9. Bailey LB, Gregory JF 3rd. Polymorphisms of methylenetetrahydrofolate reductase and other enzymes: metabolic significance, risks and impact on folate requirement. J Nutr. 1999;129:919-22.

10. Jacques PF, Bostom AG, Williams RR, Ellison RC, Eckfeldt JH, Rosenberg IH, et al. Relation between folate status, a common mutation in methylenetetrahydrofolate reductase, and plasma homocysteine concentrations. Circulation. 1996;93:7-9.

11. Izmirli M, Alptekin D, Topcuoglu MS, Guzel Al. Investigation of methylene tetrahydrofolate reductase gene polymorphisms in coronary by-passed patients due to coronary atherosclerosis etiology. Turkiye Klinikleri J Cardiovasc Sci. 2009;21:303-8.

12. Izmirli M, Inandiklioglu N, Abat D, Alptekin D, Demirhan O, Tansug Z, et al. MTHFR gene polymorphisms in bladder cancer in the Turkish population. Asian Pac $\mathrm{J}$ Cancer Prev. 2011;12:1833-5.

13. Vasku V, Bienertova-Vasku J, Necas M, Vasku A. MTHFR (methylenetetrahydrofolate reductase) C677T polymorphism and psoriasis. Clin Exp Med. 2009;9:327-31.

14. Fleischer AB Jr, Feldman SR, Rapp SR, Reboussin DM, Exum ML, Clark AR, et al. Disease severity measures in a population of psoriasis patients: the symptoms of psoriasis correlate with self-administered psoriasis area severity index scores. J Invest Dermatol. 1996;107:26-9.

15. Miller SA, Dykes DD, Polesky HF. A simple salting out procedure for extracting DNA from human nucleated cells. Nucleic Acids Res. 1988;16:1215.

16. Baiqiu W, Songbin F, Guiyin Z, Pu L. Study of the relationship between psoriasis and the polymorphic site C677T of methylenetetrahydrofolate reductase. Chin Med Sci J. 2000;15:119-20.

\section{CONCLUSION}

MTHFR polymorphisms are influenced by ethnic background. We focused on the southern Turkish population with psoriasis and found that MTHFR C677T polymorphism was associated with psoriasis. The limitation of our study was sample size and use of methotrexate. To obtain definitive data, a larger sample size and the data of evaluated drug's efficacy is required.]

\section{ACKNOWLEDGMENTS}

This study was supported by the Mustafa Kemal University Research Fund (BAP: 11780).

17. Karabacak E, Aydin E, Ozcan 0, Dogan B, Gultepe M, Cosar A, et al Methylenetetrahydrofolate reductase (MTHFR) 677C >:T gene polymorphism as a possible factor for reducing clinical severity of psoriasis. Int J Clin Exp Med. 2014;7:697-702.

18. Asefi M, Vaisi-Raygani A, Khodarahmi R, Nemati $H$, Rahimi Z, Vaisi-Raygani $\mathrm{H}$, et al. Methylenetetrahydrofolate reductase ( $r$ 1801133) polymorphism and psoriasis: contribution to oxidative stress, lipid peroxidation and correlation with vascular adhesion protein 1, preliminary report. J Eur Acad Dermatol Venereol. 2014;28:1192-8

19. Liew SC, Das-Gupta E, Wong SF, Lee N, Safdar N, Jamil A. Association of methylenetetrahydrofolate reductase (MTHFR) $677 \mathrm{C}>$ T gene polymorphism and homocysteine levels in psoriasis vulgaris patients from Malaysia: a case-control study. Nutr J. 2012;11:1.

20. Weger $\mathrm{W}$, Hofer A, Stanger $\mathrm{O}$, Wolf $\mathrm{P}$, El-Shabrawi $\mathrm{Y}$, Renner $\mathrm{W}$, et al. The methylenetetrahydrofolate reductase $677 \mathrm{C}>\mathrm{T}$ gene polymorphism is not associated with chronic plaque psoriasis. Exp Dermatol. 2008;17:748-51.

21. Chandran V, Siannis F, Rahman P, Pellett FJ, Farewell VT, Gladman DD.. Folate pathways enzyme gene polymorphisms and the efficacy and toxicity of methotrexate in psoriatic arthritis. J Rheumatol. 2010;37:1508-12.

22. Campalani E, Arenas M, Marinaki AM, Lewis CM, Barker JN, Smith CH Polymorphisms in folate, pyrimidine, and purine metabolism are associated with efficacy and toxicity of methotrexate in psoriasis. $\mathrm{J}$ Invest Dermatol. 2007;127:1860-7.

23. Taraborelli M, Andreoli L, Archetti S, Ferrari M, Cattaneo R, Tincani A Methylenetetrahydrofolate reductase polymorphisms and methotrexate: No association with response to therapy or with drug related adverse events in an Italian population of rheumatic patients. Clin Exp Rheumatol. 2009;27:499-502.

24. Warren RB, Smith RL, Campalani E, Eyre S, Smith CH, Barker JN, et al. Outcomes of methotrexate therapy for psoriasis and relationship to genetic polymorphisms. Br J Dermatol. 2009;160:438-41.

How to cite this article: Izmirli M, Bulbul-Sen B, Rifaioglu E, Gogebakan B, Aldemir O, Sen T, Ekiz O, Alptekin D. The methylenetetrahydrofolate reductase (MTHFR) C677T polymorphism in psoriasis in Southern Turkey. An Bras Dermatol. 2016;91(5):611-3. 